\title{
BEARING CAPACITY OF COLD-FORMED UNLIPPED CHANNELS WITH RESTRAINED FLANGES UNDER EOF AND IOF LOAD CASES
}

\author{
Balasubramaniam Janarthanan $^{1}$, Mahen Mahendran ${ }^{2}$ and Shanmuganathan Gunalan ${ }^{3}$ \\ ${ }^{1,2,3}$ Queensland University of Technology, Brisbane, QLD 4000, Australia
}

\begin{abstract}
Bearing failure is a form of localized failure that occurs when thin-walled coldformed steel sections are subjected to concentrated loads or support reactions. To determine the bearing capacity of cold-formed channel sections, a unified design equation with different bearing coefficients is given in the current North American specification AISI S100 and Australian/New Zealand standard AS/NZS 4600. However, coefficients are not available for unlipped channel sections that are normally fastened to supports through their flanges. Eurocode 3 Part 1.3 includes bearing capacity equations for different load cases, but does not distinguish between fastened and unfastened support conditions. Therefore, an experimental study was conducted to determine the bearing capacities of these sections as used in floor systems. Twenty-eight web bearing tests on unlipped channel sections with restrained flanges were conducted under End One Flange (EOF) and Interior One Flange (IOF) load cases. Using the results from this study, a new equation was proposed within the AISI S100 and AS/NZS 4600 guidelines to determine the bearing capacities of cold-formed unlipped channels with flanges fastened to supports. A new design rule was also proposed based on the direct strength method.
\end{abstract}

Keywords: Cold-formed unlipped channel sections, Bearing capacity, EOF and IOF load cases, Fastened and unfastened to supports, Experimental study, Design rules, Direct strength method 


\section{Introduction}

Cold-formed steel members have been gaining in popularity over hot-rolled steel members due to their high strength to weight ratio, mass production, accurate detailing and ease of fabrication. Among these cold-formed types, channel sections are commonly used as bearers and joists in floor systems for residential, industrial and commercial buildings as shown in Fig. 1. These conventional channel sections are mainly classified as lipped channel sections (with stiffened flanges) and unlipped channel sections (with unstiffened flanges). Such channel sections are used in floor systems with bolted and welded connections. However, these cold-formed steel sections are risk of localized failures in their slender plate elements, which should be considered in their designs.

Web bearing failure, also known as web crippling failure, is one such failure in thin-walled, cold-formed steel beams due to concentrated loads or support reactions. The bearing capacities and failure modes of cold-formed steel channel sections mainly depend on the loading types, locations, and connection types. Fig. 2 shows the different web bearing/crippling failures of cold-formed unlipped channel sections under the End-OneFlange load case. In Fig. 2a the flanges have rotated about the web/flange junction. However, in Fig. $2 \mathrm{~b}$ such rotation has been restrained by the bolted connection. The current North American specification [1], Australian/New Zealand standard [2] and Eurocode 3 Part 1.3 [3] specify four types of load case - End One Flange (EOF), Interior One Flange (IOF), End Two Flange (ETF) and Interior Two Flange (ETF) - by considering load types and failure locations as shown in Fig. 3. The failure type is considered as end loading if the failure region is within $1.5 d_{1}$ from the edge of the specimen. Otherwise, it is considered as interior loading failure. The one flange loading condition is considered if the distance between the edges of two 
opposite bearing plates is greater than $1.5 d_{1}$. Otherwise, it is considered as two-flange loading.

Since 1940 many experimental studies have been performed on cold-formed steel channel sections with unfastened [4], [5] and fastened support conditions [6], [7]. Current design rules for the bearing capacities of cold-formed steel members in the North American specification AISI S100 [1], Australian/New Zealand standard AS/NZS 4600 [2] and Eurocode specification EC3 Part 1.3 [3] were developed based on these past experimental studies. The current North American specification [1] and Australian/New Zealand standard [2] use the unified bearing capacity equation with different bearing coefficients developed by Prabakaran [8]. These bearing coefficients are based on the flange types of channel sections and support conditions. However, no bearing coefficients are available for unlipped channel sections with flanges fastened to supports. Eurocode 3 Part 1.3 [3] does not even distinguish between fastened and unfastened support conditions. AS/NZS 4600 uses bearing capacity while AISI S100 uses web crippling strength, and in this paper bearing capacity is used in most cases.

Hetrakul and $\mathrm{Yu}$ [5] reported an up to $10 \%$ increase in bearing capacity due to fastened supports compared with unfastened supports, whereas Bakta et al. [9] reported a 14.7\% using only a few test results only. Young and Hancock [10] reported a bearing capacity increase of $10-15 \%$ for stocky cold-formed unlipped channel sections (4-6 mm thick) under two flange load cases when only one flange was fastened to supports. Therefore, predictions using the bearing coefficients for unfastened support conditons may be uneconomical for channel sections with flanges fastened to supports. Young and Hancock [10] also reported that the current bearing design equations were unconservative for stocky cold-formed unlipped channel sections under all load cases. Therefore it is considered that the current cold-formed steel design equations do not predict the bearing capacities of unlipped channels accurately. 
Futhermore, the test set-ups and specimen lengths used in past research studies (Young and Hancock [10] and Macdonald et al. [11]) were different. Recently the AISI standard test method [12] was updated; it now specifies suitable guidelines for test setups and specimen lengths to make bearing tests consistent.

The AISI standard test method [12] recommends the use of two opposing channel sections in a box-beam arrangement to make the web crippling test specimen laterally and torsionally stable. It also suggests the minimum length of test specimens for all four loading cases as

EOF Loading: $L_{\min }=3 d_{1}+3 l_{b}$

IOF Loading: $L_{\min }=3 d_{1}+3 l_{b}$

ETF Loading: $L_{\min }=3 d_{1}$

ITF Loading: $L_{\min }=5 d_{1}$

where $d_{l}$ is the depth of a flat portion of the web of the specimen and $l_{b}$ is the bearing length. This standard test method [12] should be followed in conducting web crippling tests.

No design equations exist for accurately predicting the bearing capacity of 'fastened supportunlipped' channel sections in the current cold-formed specifications. Therefore this research is aimed at investigating the bearing behavior and capacity of cold-formed steel unlipped channel sections with their flanges fastened to supports under EOF and IOF load cases. Bearing tests were undertaken using the recently updated AISI standard test method [12]. Test results were compared with current design rules, but they gave inconsistent predictions. Therefore a new equation was proposed within the guidelines of AISI S100 and AS/NZS 4600. New design rules were also developed under the direct strength method format.

\section{Current Design Rules}

This study considered the design rules for the bearing capacity of cold-formed steel channel sections in North American specification (AISI S100), Australian/ New Zealand standards 
(AS/NZS 4600) and Eurocode 3 Part 1.3. The design rules in AISI S100 are identical to those in AS/NZS 4600 and so reference is only made to AISI S100 in this paper.

\subsection{AISI S100 (NAS 2007)}

The unified bearing capacity design equation (Eq. (2)) with different specific bearing coefficients is given in the current AISI S100 specification.

$$
R_{b}=C t_{w}^{2} f_{y} \sin \theta\left(1-C_{r} \sqrt{\frac{r_{i}}{t_{w}}}\right)\left(1+C_{l} \sqrt{\frac{l_{b}}{t_{w}}}\right)\left(1-C_{w} \sqrt{\frac{d_{1}}{t_{w}}}\right)
$$

where:

$\mathrm{C}$

$\mathrm{C}_{\mathrm{r}}, \mathrm{C}_{1}, \mathrm{C}_{\mathrm{w}} \quad$ coefficients for inside bend radius, bearing length and web slenderness respectively

$\mathrm{t}_{\mathrm{w}} \quad$ web thickness

fy $\quad$ yield stress

$\theta$

ri

$\mathrm{lb}$

$\mathrm{d}_{1}$ angle between the planes of the web and the bearing surface

inside bend radius

depth of the flat portion of web measured along plane of web. bearing length

These bearing coefficients $\left(\mathrm{C}, \mathrm{C}_{\mathrm{r}}, \mathrm{C}_{\mathrm{l}}, \mathrm{C}_{\mathrm{w}}\right)$ depend on the load cases, support conditions and flange types. However, no coefficients are available for determining the bearing capacity of cold-formed unlipped channel sections with flanges fastened to supports ('fastened support unstiffened flange' condition). Hence the coefficients available in AISI S100 for 'unfastened support - unstiffened flange' and 'fastened support - stiffened flange' conditions were considered in this study. These coefficients are shown in Table 1. 


\subsection{Eurocode 3 Part 1.3}

Eurocode 3 Part 1.3 specifies different design equations for different load cases to determine the bearing capacity of cold-formed steel sections. However, the code does not consider fastened and unfastened support conditions as in AISI S100. Eqs. (3) and (4) are used to determine the bearing capacities of unlipped channel sections under EOF and IOF load cases respectively.

For the EOF load case

$$
\begin{aligned}
& \text { If } l_{b} / t \leq 60, \mathrm{R}_{\mathrm{b}}=\mathrm{k}_{1} \mathrm{k}_{2} \mathrm{k}_{3}\left[5.92-\frac{\mathrm{h}_{\mathrm{w}}}{132 \mathrm{t}_{\mathrm{w}}}\right]\left[1+0.01 \frac{\mathrm{l}_{\mathrm{b}}}{\mathrm{t}_{\mathrm{w}}}\right] \mathrm{t}_{w}^{2} \mathrm{f}_{\mathrm{y}} / \gamma_{\mathrm{M} 1} \\
& \text { If } l_{b} / t>60, \mathrm{R}_{\mathrm{b}}=\mathrm{k}_{1} \mathrm{k}_{2} \mathrm{k}_{3}\left[5.92-\frac{\mathrm{h}_{\mathrm{w}}}{132 \mathrm{t}_{\mathrm{w}}}\right]\left[0.71+0.015 \frac{\mathrm{l}_{\mathrm{b}}}{\mathrm{t}_{\mathrm{w}}}\right] \mathrm{t}_{w}^{2} \mathrm{f}_{\mathrm{y}} / \gamma_{\mathrm{M} 1}
\end{aligned}
$$

For the IOF load case

$$
\begin{aligned}
& \text { If } l_{b} / t \leq 60, \mathrm{R}_{\mathrm{b}}=\mathrm{k}_{1} \mathrm{k}_{2} \mathrm{k}_{3}\left[14.7-\frac{\mathrm{h}_{\mathrm{w}}}{49.5 \mathrm{t}_{\mathrm{w}}}\right]\left[1+0.007 \frac{\mathrm{l}_{\mathrm{b}}}{\mathrm{t}_{\mathrm{w}}}\right] \mathrm{t}_{\mathrm{w}}^{2} \mathrm{f}_{\mathrm{y}} / \gamma_{\mathrm{M} 1} \\
& \text { If } l_{b} / t>60, \mathrm{R}_{\mathrm{b}}=\mathrm{k}_{1} \mathrm{k}_{2} \mathrm{k}_{3}\left[14.7-\frac{\mathrm{h}_{\mathrm{w}}}{49.5 \mathrm{t}_{\mathrm{w}}}\right]\left[0.75+0.011 \frac{\mathrm{l}_{\mathrm{b}}}{\mathrm{t}_{\mathrm{w}}}\right] \mathrm{t}_{w}^{2} \mathrm{f}_{\mathrm{y}} / \gamma_{\mathrm{M} 1}
\end{aligned}
$$

where:

$\mathrm{k}_{1}, \mathrm{k}_{4} \quad$ coefficients dependent on the strength of the material

$\mathrm{k}_{2}, \mathrm{k}_{5} \quad$ coefficients dependent on the inside bend radius to the thickness ratio

$\mathrm{k}_{3} \quad$ coefficients dependent on the angle between the flange and web

$\mathrm{h}_{\mathrm{w}} \quad$ web height between flange mid-lines

$\gamma_{\mathrm{M} 1} \quad$ partial safety factor

(Other symbols are as defined in Eq.2.)

\section{Experimental Study}

Twenty-eight tests were conducted to investigate the web bearing/crippling behaviour of cold-formed unlipped channel sections with flanges fastened to bearing plates under EOF and 
IOF load cases. These sections were made from G450 high-strength steel with a minimum yield strength of $450 \mathrm{MPa}$. Tensile coupon tests were also conducted according to AS1391 [13], and the results obtained are shown in Table 2. Tables 3 and 4 show the measured section depth $d$, flange width $b_{f}$, thickness $t_{w}$, internal radius $r_{i}$ and the specimen length $L$. The specimen length L was chosen according to the recently updated AISI test method [12]. Three different bearing lengths $\left(l_{b}=50,100\right.$ and $\left.150 \mathrm{~mm}\right)$ were used for both EOF and IOF load cases. Two identical channel sections were connected by angles to the top and bottom flanges at quarter points of the specimen length, and a torsionally stable box arrangement was developed as shown in Fig. 4. To ensure full contact between the loading plate and the channel section, the bearing plate width was greater than the box section width. The bearing plates were connected to half rounds bars to simulate a pinned condition. The flanges of the test channel sections were fastened to the bearing plates using M12 bolts. For the EOF load case, both sides of the web at mid-span were reinforced using $20 \mathrm{~mm}$ thick and $100 \mathrm{~mm}$ wide web side plates to avoid any failure at mid-span. For the IOF load case, these plates were connected at both ends of the specimen to eliminate end failures.

The load was applied until failure using an Instron testing machine. All the specimens tested for the EOF load case failed due to web crippling as shown in Fig. 5a - except Test 5, which failed due to combined web crippling and bending. Test 5 results were thus excluded from further analysis. In all the specimens tested for the IOF load case, the failure was initiated by web crippling followed by flange crushing as shown in Fig. 5b. Tables 3 and 4 show the experimental bearing capacities of unlipped channels obtained for EOF and IOF load cases respectively. LVDTs were used to measure the lateral deflection of the web element of each test section. For the EOF load case, two LVDTs were used, one on each section, but located at opposite ends at one-third the specimen depth from the fastened supports. For the IOF load case, two LVDTs were placed at mid-span at one-third the specimen depth from the top 
flange. The load versus vertical displacement of the loading plate and the load versus lateral deflection of the web element were plotted as shown in Fig. 6. Experimental results for web bearing (web crippling) capacities were compared with corresponding AISI S100 predictions using the available web bearing (web crippling) coefficients and Eurocode predictions as shown in Tables 3 and 4, where the last three columns present the ratio of experimental to predicted bearing capacities (a value less than 1.0 means unsafe prediction).

Table 3 shows that the use of 'unfastened support-unstiffened flange' (AISI S100 (1)) coefficients generally underestimated the bearing capacity of unlipped channel sections with flanges fastened to supports, especially for sections with larger web slenderness ratios $\left(\mathrm{d}_{1} / \mathrm{t}_{\mathrm{w}}\right)$ and smaller bearing lengths, whereas the predictions using the 'fastened support-stiffened flange' (AISI S100 (2)) coefficients are not safe for the EOF load case. On the other hand, Eurocode specifications underestimated the bearing capacity of these sections under the EOF load case by more than $100 \%$. For the IOF load case, Table 4 shows that the use of 'unfastened support-unstiffened flange' (AISI S100 (1)) coefficients predicted the bearing capacity of unlipped channel sections with flanges fastened to supports inconsistently, ie. overestimation for sections with smaller web slenderness ratios and underestimation for sections with higher ratios. The predictions using the 'fastened support-stiffened flange' (AISI S100 (2)) coefficients were unconservative compared with experimental results. However, Eurocode design equations (Eqs. 4a and $4 \mathrm{~b}$ ) appear to predict the bearing capacities better than AISI S100 for this load case.

\section{Proposed design equations}

The predictions from the current design rules are inconsistent for the unlipped channel sections with flanges fastened to supports for both EOF and IOF load cases as shown in Tables 3 and 4 respectively. Attempts to use the bearing coefficients available for 'unfastened 
support-unstiffened flange' or 'fastened support-stiffened flange' cases were found to be unsuccessful. Therefore, new design equations are proposed within the scope of the AISI S100 and DSM guidelines.

\subsection{AISI S100}

Eq. (2) with improved bearing coefficients for proposed for accurately predicting the bearing capacity of cold-formed steel unlipped channel sections with flanges fastened to supports. Table 5 presents the proposed bearing coefficients and the new comparisons with experimental capacities. The mean and COV values have been improved to 1.00 and 0.06 respectively for the EOF load case and 1.00 and 0.07 for IOF. Tables 6 and 7 present the details of comparison for each test.

\section{Reliability Analysis}

The capacity reduction factor $\left(\phi_{w}\right)$ accounts for variations in the material, fabrication and loading effects. The capacity reduction factor depends on load factors in the dead $\alpha_{D}$ and live $\alpha_{\mathrm{L}}$ load combination, permissible dead to live load ratio $\mathrm{D} / \mathrm{L}$ and target reliability index $\beta$. The factored resistance forces are always greater or equal to factored loads to ensure the safe design of structures as given in Eq. (5):

$\phi \mathrm{R}_{\mathrm{n}}=\mathrm{c}\left(\alpha_{\mathrm{D}} \mathrm{D}_{\mathrm{n}}+\alpha_{\mathrm{L}} \mathrm{L}_{\mathrm{n}}\right)$

The dead and live load combination is $1.2 \mathrm{DL}+1.6 \mathrm{LL}$ and the permissible dead-to-live load ratio $\mathrm{D} / \mathrm{L}$ is $1 / 5$ in the USA as specified in the old American specification [14]. The relationship between reliability index $\beta$ and capacity reduction factor $\phi_{\mathrm{w}}$ was derived as Eq. (6):

$\phi_{\mathrm{w}}=\mathrm{CM}_{\mathrm{m}} \mathrm{F}_{\mathrm{m}} \mathrm{P}_{\mathrm{m}} \mathrm{e}^{-\beta_{0} \sqrt{\left\{\mathrm{v}_{\mathrm{m}}^{2}+\mathrm{V}_{\mathrm{f}}^{2}+\mathrm{C}_{\mathrm{p}} \mathrm{V}_{\mathrm{p}}^{2}+\mathrm{V}_{\mathrm{q}}^{2}\right\}}}$

In Eq. (6), $C=1.521$ for the American specification [14]. The statistical parameters are obtained from Table F1 in the North American specification [1] for the web crippling 
strength, where $\mathrm{M}_{\mathrm{m}}=1.1, \mathrm{~V}_{\mathrm{m}}=0.1, \mathrm{~F}_{\mathrm{m}}=1.0$, and $\mathrm{V}_{\mathrm{F}}=0.05$. Parameters $\mathrm{P}_{\mathrm{m}}$ and $\mathrm{V}_{\mathrm{m}}$ are, respectively, the mean value and the coefficient of variation of tested-to-predicted load ratio. Statistical parameter $\mathrm{V}_{\mathrm{q}}$ is the coefficient of variation of load effects and depends on the ratio of dead to live loads, equal to 0.207 in this instance. Here, $C_{p}$ is a correction factor for a small

number of tests and given by $\left[1+\frac{1}{n}\right]\left[\frac{m}{m-2}\right]$; where $\mathrm{n}=$ number of tests and $\mathrm{m}=$ degree of freedom $=\mathrm{n}-1$.

Using Eq. (6) with the mean and COV values from Tables 6 and 7, the capacity reduction factors $\left(\phi_{\mathrm{w}}\right)$ were determined and are shown in Table 5.

\subsection{Direct Strength Method}

The direct strength method (DSM) represents an alternative to the traditional effective width approach, and was formally adopted in the North American specification [1] in 2004. The DSM uses the elastic buckling load Rbcr and the yield load Rby of the section. The DSM is currently included in the North American specification in order to determine the ultimate capacities of cold-formed steel columns and beams subjected to flexural, flexural-torsional, local and distortional buckling effects. However, the DSM does not include web crippling. Hence, suitable design rules for the bearing capacity $\mathrm{R}_{\mathrm{b}}$ of unlipped channel sections with flanges fastened to supports were developed within the scope of the DSM format. Eqs. (7) and (9) show the proposed DSM bearing capacity equations.

For EOF load case:

$$
\frac{\mathrm{R}_{\mathrm{b}}}{\mathrm{R}_{\mathrm{by}}}=0.18\left[1-0.001\left(\frac{\mathrm{R}_{\mathrm{bcr}}}{\mathrm{R}_{\text {by }}}\right)^{0.36}\right]\left(\frac{\mathrm{R}_{\mathrm{bcr}}}{\mathrm{R}_{\mathrm{by}}}\right)^{0.36}
$$

where

$$
\mathrm{R}_{\mathrm{by}}=\mathrm{f}_{\mathrm{y}} \mathrm{t}_{\mathrm{w}}\left(\mathrm{l}_{\mathrm{b}}+\frac{\mathrm{d}_{1}}{2}\right)
$$


For IOF load case:

$\frac{\mathrm{R}_{\mathrm{b}}}{\mathrm{R}_{\text {by }}}=0.19\left[1-0.001\left(\frac{\mathrm{R}_{\mathrm{bcr}}}{\mathrm{R}_{\text {by }}}\right)^{0.39}\right]\left(\frac{\mathrm{R}_{\mathrm{bcr}}}{\mathrm{R}_{\text {by }}}\right)^{0.39}$

where

$$
\begin{aligned}
& \mathrm{R}_{\mathrm{by}}=\mathrm{f}_{\mathrm{y}} \mathrm{t}_{\mathrm{w}}\left(\mathrm{l}_{\mathrm{b}}+\mathrm{d}_{1}\right) \\
& \mathrm{R}_{\mathrm{bcr}}=\frac{\pi^{2} \mathrm{Ek} \mathrm{t}_{\mathrm{w}}{ }^{3}}{12\left[1-\mathrm{v}^{2}\right] \mathrm{d}_{1}} \\
& \lambda=\sqrt{\frac{\mathbf{R}_{\mathrm{by}}}{\mathbf{R}_{\mathrm{bcr}}}}
\end{aligned}
$$

The critical buckling load can be calculated using Eq. (11) if the elastic buckling coefficient $\mathrm{k}$ is known. However, the elastic buckling coefficient $\mathrm{k}$ is unknown for the web bearing of cold-formed unlipped channel sections with flanges fastened to supports. Therefore, in this study, finite element buckling analyses of the sections tested were undertaken to determine the critical buckling loads $\mathrm{R}_{\mathrm{bcr}}$ for EOF and IOF load cases. The elastic buckling coefficients $\mathrm{k}$ were also determined using the finite element analysis results and are shown in Tables 6 and 7. The yield loads $\mathrm{R}_{\text {by }}$ of the sections for EOF and IOF load cases were determined using Eq. (8) and Eq. (10) respectively, which are based on $45^{\circ}$ load dispersion to mid-web height. Finally, the web bearing predicted by this design method (DSM) was compared with test results in Tables 6 and 7 as Test/DSM capacity ratios.

The last columns of Tables 6 and 7 show that the proposed DSM equations are able to predict accurately the bearing capacities of cold-formed steel unlipped channel sections with flanges fastened to supports. The mean and COV values are 1.02 and 0.06 respectively for the EOF load case and 1.00 and 0.06 for IOF.

Experimental ultimate bearing capacity results were also processed within the DSM format and are compared in Figs. 7(a) and (b) for EOF and IOF load cases respectively, where the 
slenderness $(\lambda)$ was calculated using Eq. (12). These figures show the non-dimensional bearing capacity curves for cold-formed steel unlipped channel sections with flanges fastened to supports and compare them with experimental results. It can be seen that the proposed DSM equations predict the bearing capacities of unlipped channel sections reasonably well.

\section{Conclusions}

This paper has presented the details and results of an experimental study of 28 bearing tests on cold-formed steel unlipped channel sections with their flanges fastened to supports under EOF and IOF load cases. The comparison of experimental bearing capacities with predictions from the current design rules (Australian/New Zealand standard, North American and Eurocode specifications) showed that these design rules predicted the bearing capacity of unlipped channel sections with flanges fastened to supports inconsistently. The use of bearing coefficients recommended for lipped channel sections fastened to supports is not acceptable as they overestimated the bearing capacities of unlipped channel sections. Hence, new bearing coefficients were proposed within AISI S100 specification to predict accurately the bearing capacities of cold-formed unlipped channel sections with fastened support (fastened support-unstiffened flange) conditions. Suitable design rules were also developed under the direct strength method format. The proposed design equations are able to predict the web bearing capacities of these sections accurately.

\section{Acknowledgements}

The authors would like to thank Australian Research Council and Austube Mills for their financial support, and QUT for providing the necessary facilities and support to this project. They would also like to thank Jimmy Chang for his assistance with experimental testing. 


\section{References}

[1] American Iron and Steel Institute (AISI) (2007), North American Specification for the Design of Cold-Formed Steel Structural Members: AISI S100, Washington, USA.

[2] Standards Australia (2005), Cold-formed steel structures, AS/NZS 4600, Sydney, Australia.

[3] European Committee for Standardization (1996) Eurocode 3, Design of steel structures: Part 1.3: General rules - Supplementary rules for cold-formed thin gauge members and sheeting, in: ENV 1993-1-3, Brussels, Belgium.

[4] Winter, G. and Pian, R.H.J. (1946), Crushing strength of thin steel webs, Engineering Experiment, Bulletinno.35, Cornell University, New York, USA.

[5] Hetrakul, N., and Yu, W.W. (1978), Structural behaviour of beam webs subjected to web crippling and a combination of web crippling and bending, Final Report, Civil Engineering Study 78-4, University of Missouri-Rolla, Rolla, Missouri, USA.

[6] Gerges, R.R. (1997), Web crippling of single web cold-formed steel members subjected to end one-flange loading, M.A.Sc. Thesis, University of Waterloo, Waterloo, Ontario, Canada.

[7] Beshara, B. and Schuster, R.M. (2000), Web crippling of Cold-formed steel C and Zsections, Proc. of $15^{\text {th }}$ International speciality conference on cold-formed steel structures, St.Louis, Missouri, USA.

[8] Prabakaran, K. (1993), Web crippling of cold-formed steel sections, Project Report, Department of Civil Engineering, University of Waterloo, Waterloo, Ontario, Canada.

[9] Bhakta, B.H., LaBoube, R.A., and Yu, W.W. (1992), The effect of flange restraint on web crippling strength, Final Report, Civil Engineering Study 92-1, University of Missouri- Rolla, Rolla, Missouri, USA. 
[10] Young, B. and Hancock, G. (2004), Web Crippling of Cold-Formed Unlipped Channels with Flanges Restrained. Thin-Walled Structures, Vol.42, pp. 911-930.

[11] Macdonald, M., Heiyantuduwa, M.A., Kotelko, M. and Rhodes, J. (2011), Web crippling behaviour of thin-walled lipped channel beams, Thin-Walled Structures, Vol.49, pp. 682-690. [12] American Iron and Steel Institute (AISI) (2013), Standard test method for determining the web crippling strength of cold-formed steel beams: AISI S909, Washington DC, USA.

[13] Standards Australia (2007), Methods for Tensile testing of metal, AS 1391, Sydney, Australia.

[14] American Iron and Steel Institute (AISI) (1996), Specification for the design of coldformed steel structural members, Washington D.C, USA. 


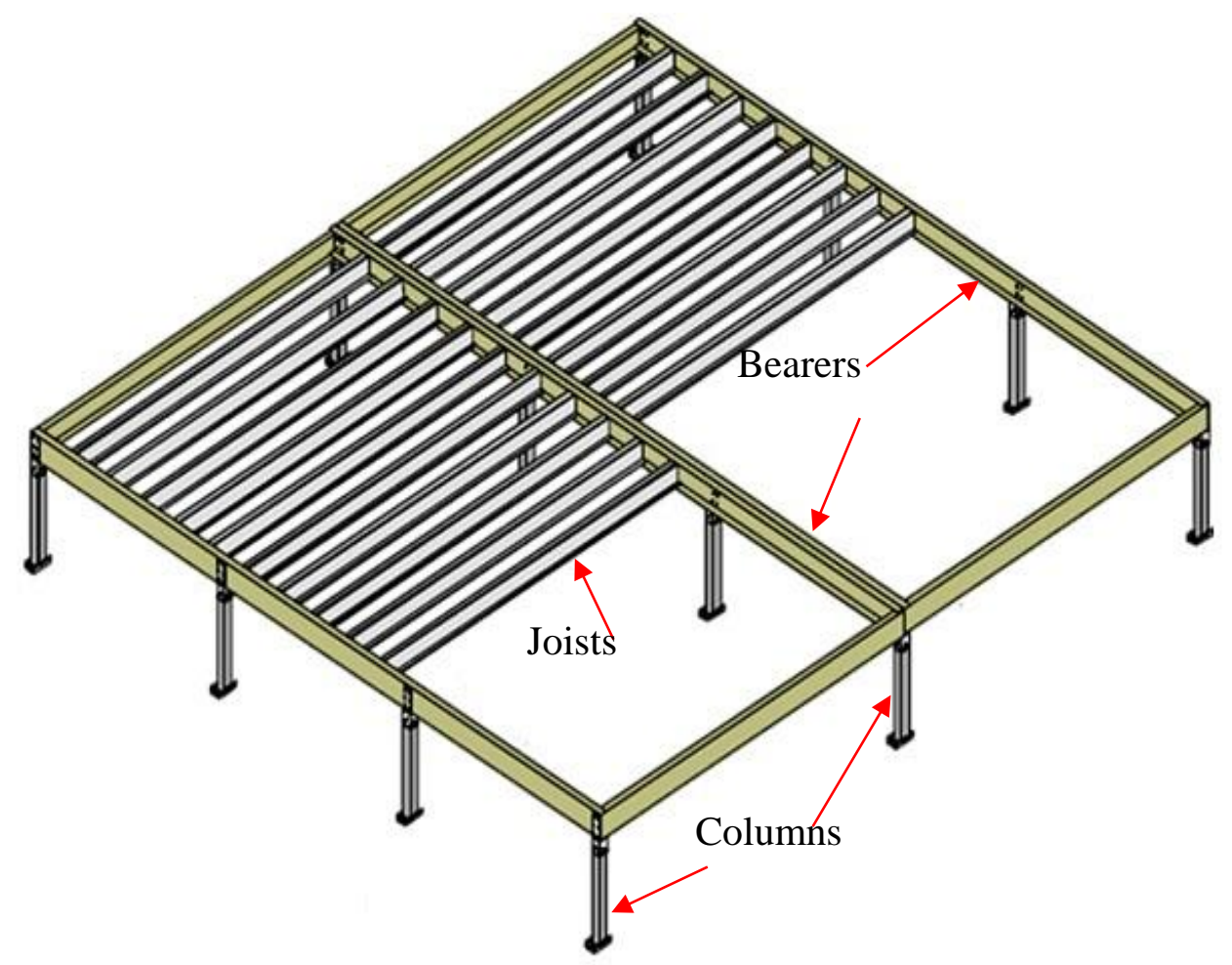

Fig. 1. Cold-formed steel floor systems

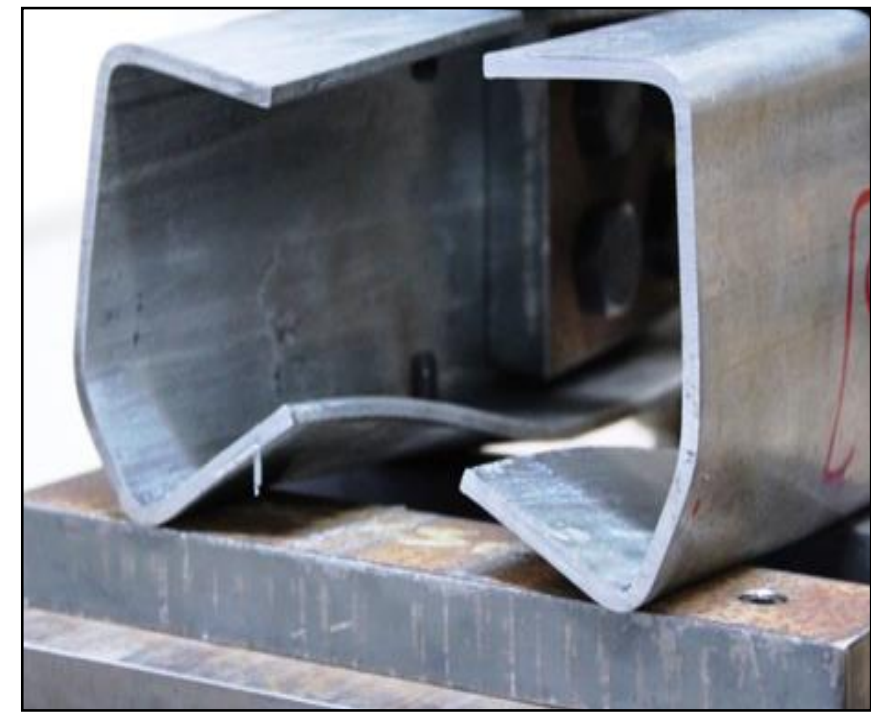

(a) Flanges unfastened to a support

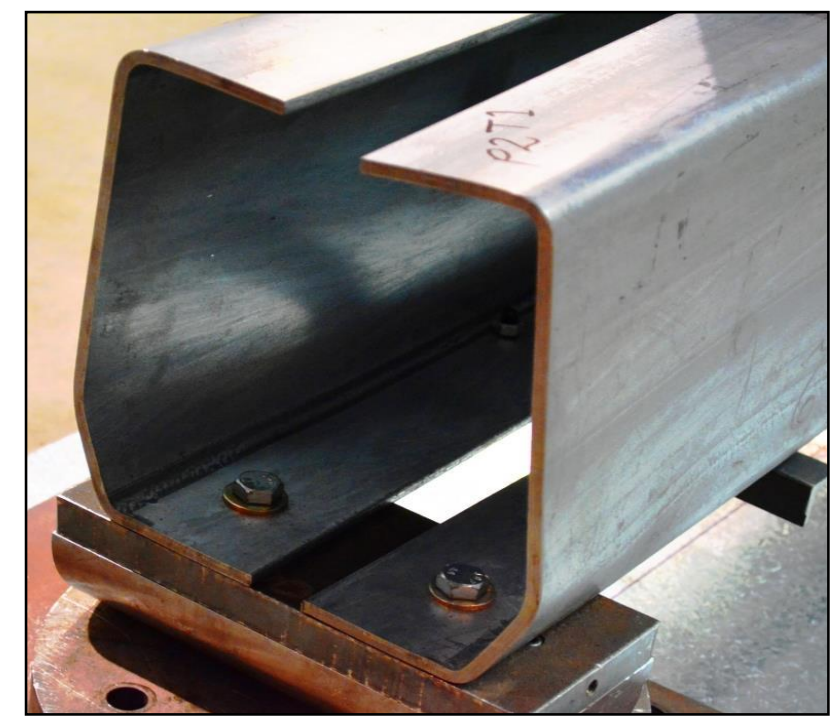

(b) Flanges fastened to a support

Fig. 2. Web crippling failures at a reaction point 


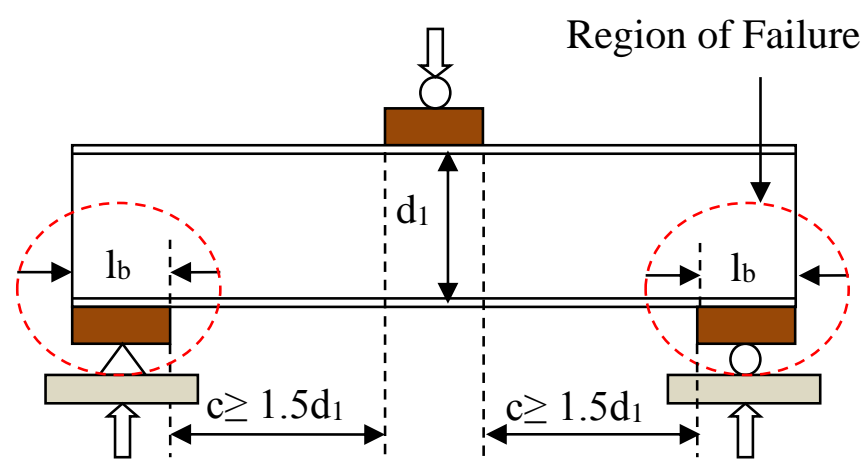

(a) End one flange loading (EOF)

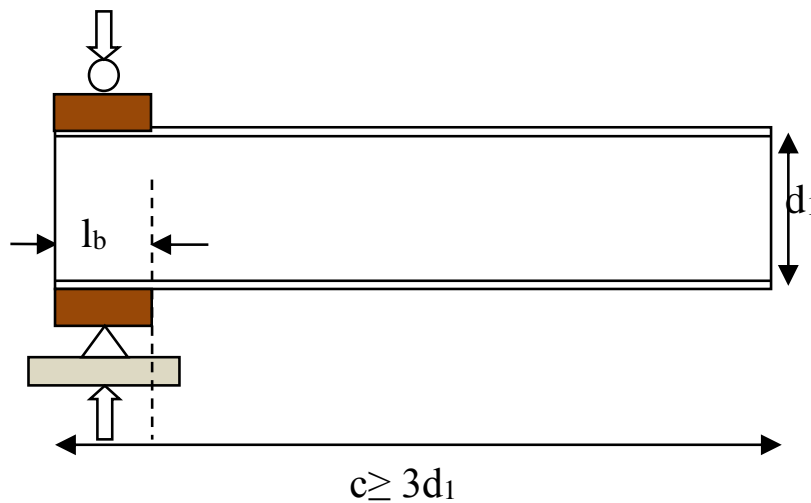

(c) End two flange loading (ETF)

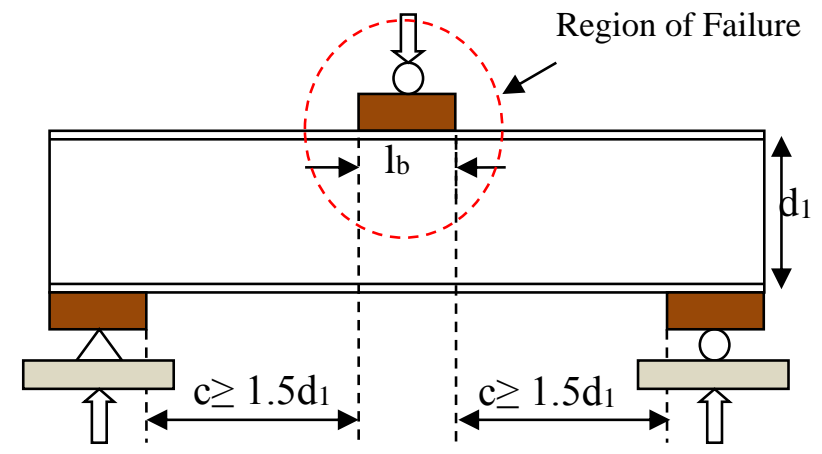

(b) Interior one flange loading (IOF)

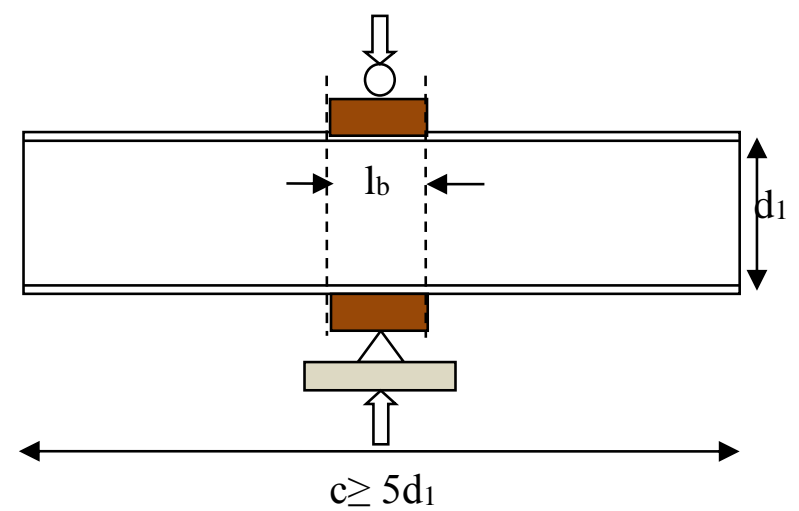

(d) Interior two flange loading (ITF)

Fig. 3. Loading conditions for web crippling tests [12]

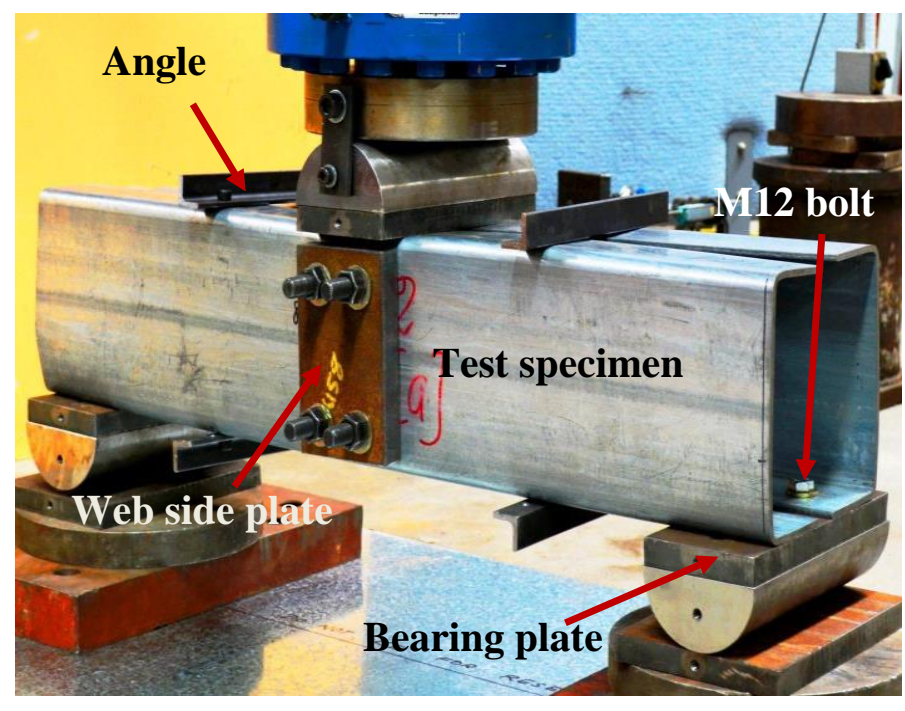

(a) EOF load case

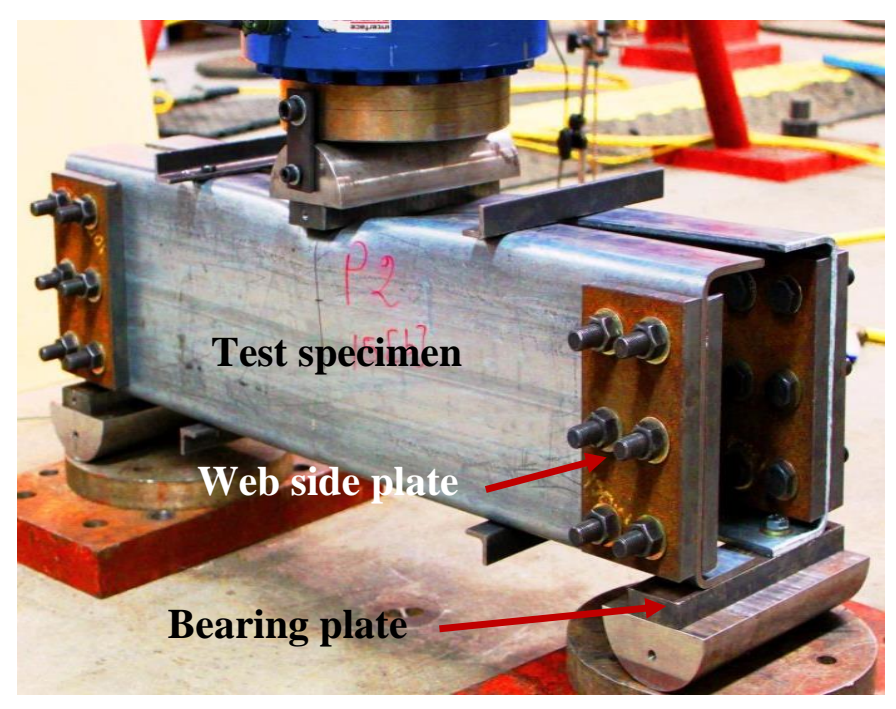

(b) IOF load case

Fig. 4. Test setups for EOF and IOF load cases 


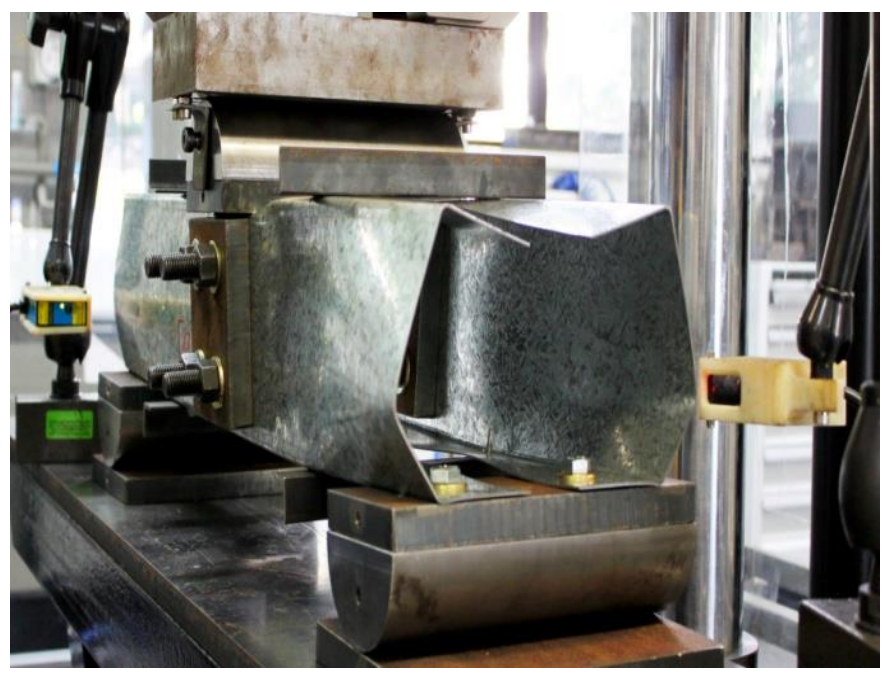

(a) EOF load case

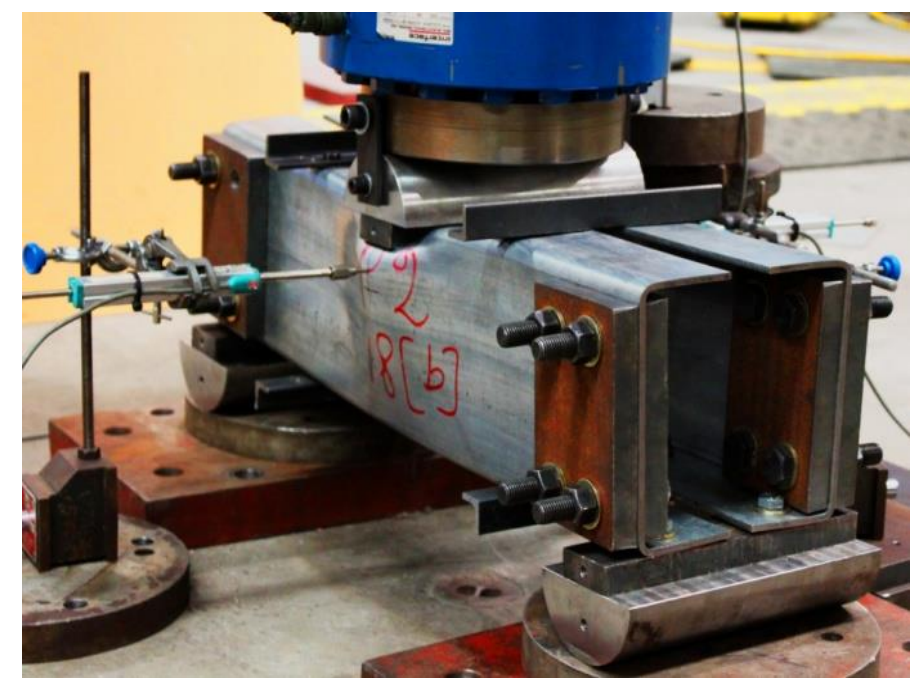

(b) IOF load case

Fig. 5. Bearing failure modes

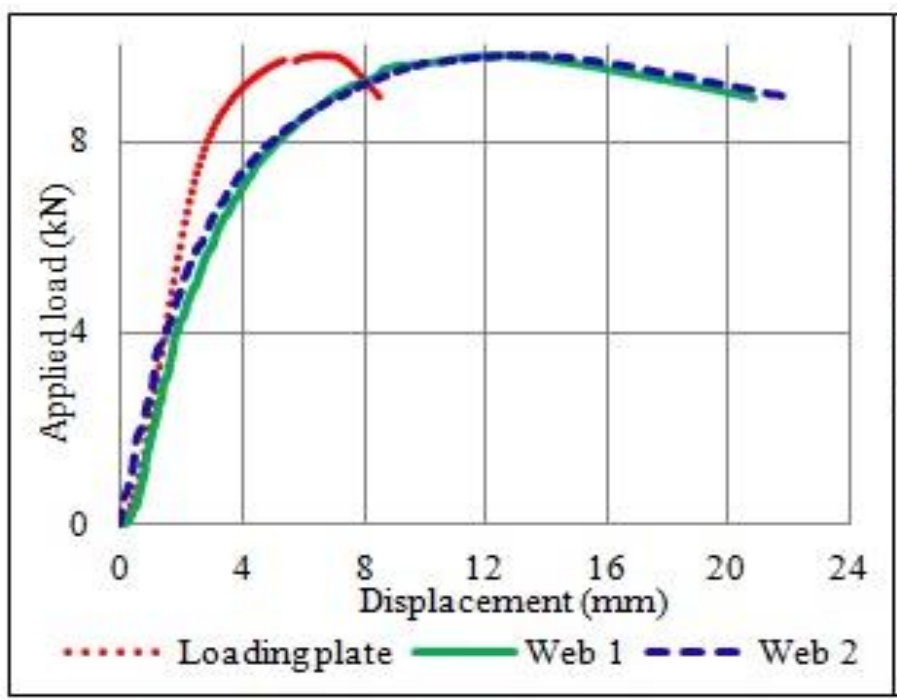

(a) EOF load case (Test 12)

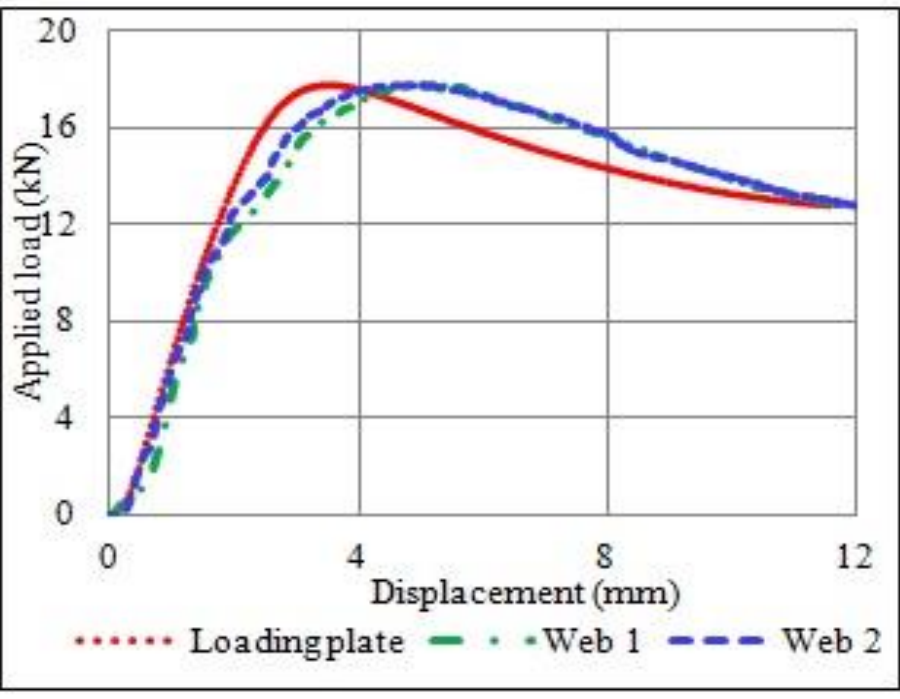

(b) IOF load case (Test 24)

Fig. 6. Typical load vs deflection curves 


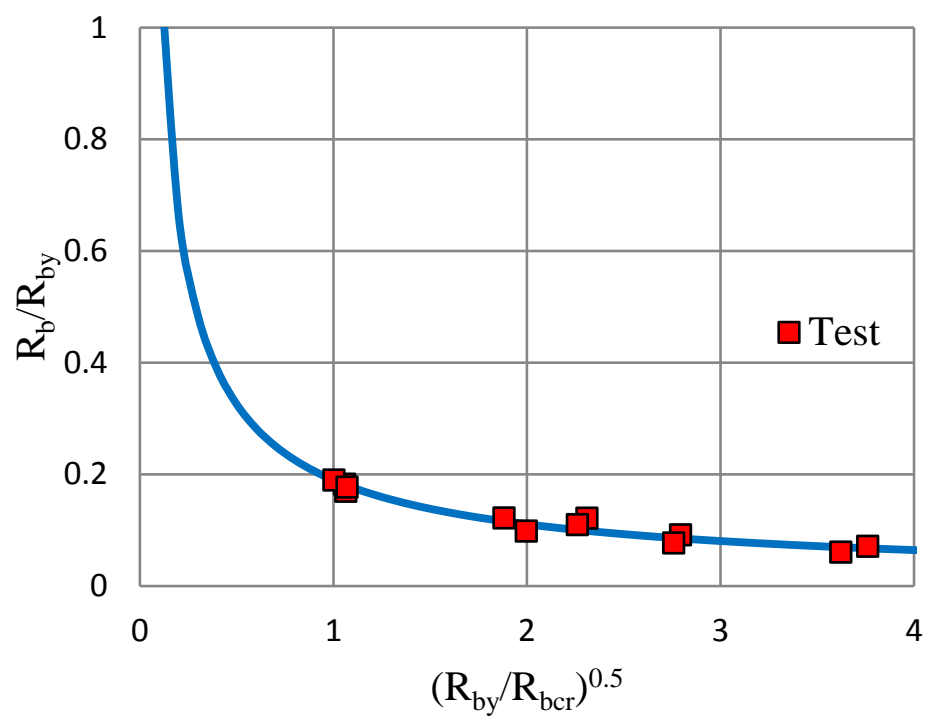

(a) EOF load case

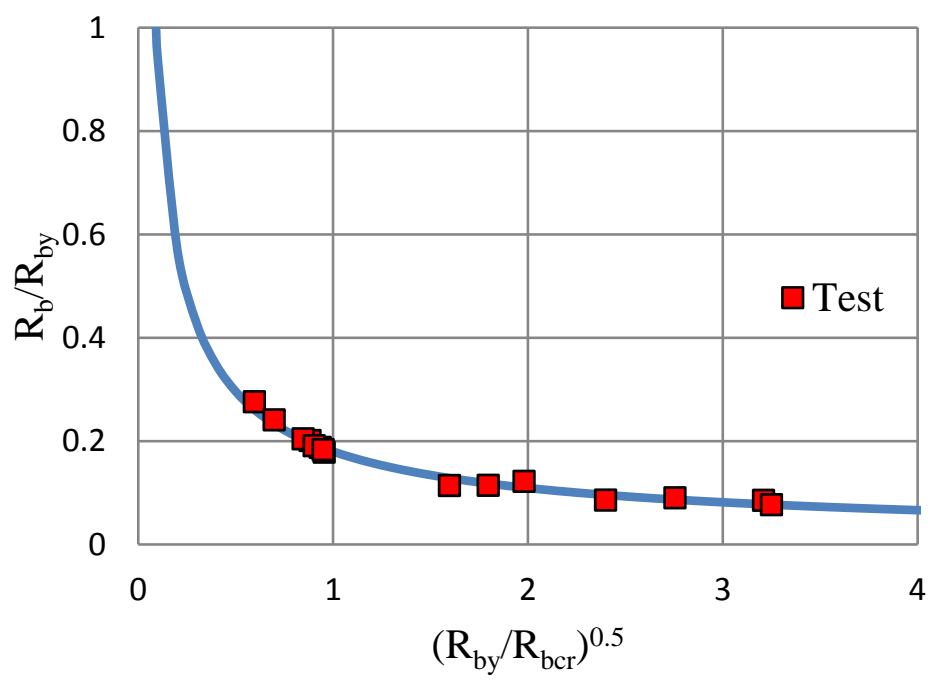

(b) IOF load case

Fig. 7. Design curves based on direct strength method 
Table 1. AISI S100 bearing coefficients for EOF and IOF load cases

\begin{tabular}{|c|c|c|c|c|c|c|c|c|c|}
\hline \multirow{2}{*}{$\begin{array}{l}\text { Support conditions and flange } \\
\text { types }\end{array}$} & \multirow{2}{*}{$\begin{array}{l}\text { Load } \\
\text { case }\end{array}$} & \multicolumn{4}{|c|}{ Coefficients } & \multicolumn{4}{|c|}{ Limitations } \\
\hline & & $\mathrm{C}$ & $\mathrm{C}_{\mathrm{r}}$ & $\mathrm{C}_{1}$ & $\mathrm{C}_{\mathrm{w}}$ & $\mathrm{r}_{\mathrm{i}} / \mathrm{t}_{\mathrm{w}}$ & $\mathrm{d}_{1} / \mathrm{t}_{\mathrm{w}}$ & $\mathrm{lb}_{\mathrm{b}} / \mathrm{t}_{\mathrm{w}}$ & $\mathrm{lb}_{\mathrm{b}} / \mathrm{d}_{1}$ \\
\hline \multirow{2}{*}{$\begin{array}{l}\text { Unlipped channels unfastened } \\
\text { to supports (AISI S100 (1)) }\end{array}$} & EOF & 4 & 0.40 & 0.60 & 0.03 & $\leq 2$ & \multirow{4}{*}{$\leq 200$} & \multirow{4}{*}{$\leq 210$} & \multirow{4}{*}{$\leq 2$} \\
\hline & IOF & 13 & 0.32 & 0.10 & 0.01 & $\leq 2$ & & & \\
\hline \multirow{2}{*}{$\begin{array}{l}\text { Lipped channels fastened to } \\
\text { supports (AISI S100 (2)) }\end{array}$} & EOF & 4 & 0.14 & 0.35 & 0.02 & $\leq 9$ & & & \\
\hline & IOF & 13 & 0.23 & 0.14 & 0.01 & $\leq 5$ & & & \\
\hline
\end{tabular}

Table 2. Mechanical properties of steel used in unlipped channel sections

\begin{tabular}{|c|c|c|c|c|c|c|c|}
\hline Section & $\begin{array}{c}230 \times 75 \times \\
6\end{array}$ & $\begin{array}{c}180 \times 75 \times \\
5\end{array}$ & $\begin{array}{c}100 \times 50 \times \\
4\end{array}$ & $\begin{array}{c}100 \times 51 \\
\times 1.5\end{array}$ & $\begin{array}{c}150 \times 64 \\
\times 1.5\end{array}$ & $\begin{array}{c}200 \times 76 \times \\
1.5\end{array}$ & $\begin{array}{c}200 \times 76 \times 2 \\
.4\end{array}$ \\
\hline$f_{y}(\mathrm{MPa})$ & 483 & 457 & 449 & 534 & 534 & 534 & 515 \\
\hline$E(\mathrm{MPa})$ & \multicolumn{8}{|c|}{200000} \\
\hline
\end{tabular}

Table 3. Test specimen details and results for EOF load case

\begin{tabular}{|c|c|c|c|c|c|c|c|c|c|c|c|}
\hline \multirow{2}{*}{ Test } & $\begin{array}{c}\text { Unlipped } \\
\text { channel } \\
\text { section }\end{array}$ & $\begin{array}{c}\mathrm{d} \\
(\mathrm{mm})\end{array}$ & $\begin{array}{c}\mathrm{b}_{\mathrm{f}} \\
(\mathrm{mm})\end{array}$ & $\begin{array}{c}\mathrm{t}_{\mathrm{w}} \\
(\mathrm{mm})\end{array}$ & $\begin{array}{c}\mathrm{r}_{\mathrm{i}} \\
(\mathrm{mm})\end{array}$ & $\begin{array}{c}\mathrm{l}_{\mathrm{b}} \\
(\mathrm{mm})\end{array}$ & $\begin{array}{c}\mathrm{L} \\
(\mathrm{mm})\end{array}$ & $\begin{array}{c}\text { Test } \\
\text { Capacity } \\
(\mathrm{kN})\end{array}$ & \multicolumn{2}{|c|}{$\begin{array}{c}\text { Test/ } \\
\text { AISI S100 }\end{array}$} & $\begin{array}{c}\text { Test/ } \\
\text { Euro } \\
\text { code }\end{array}$ \\
\hline 1 & $230 \times 75 \times 6$ & 229.8 & 74.8 & 5.88 & 8.0 & 100 & 940 & 103.9 & 1.02 & 0.86 & 1.58 \\
\hline 2 & $230 \times 75 \times 6$ & 229.5 & 74.8 & 5.93 & 8.0 & 150 & 1140 & 121.8 & 1.01 & 0.88 & 1.70 \\
\hline 3 & $180 \times 75 \times 5$ & 179.8 & 75.2 & 4.66 & 5.0 & 100 & 840 & 72.8 & 1.00 & 0.93 & 1.62 \\
\hline 4 & $180 \times 75 \times 5$ & 179.9 & 75.2 & 4.64 & 5.0 & 150 & 990 & 86.4 & 1.03 & 0.97 & 1.78 \\
\hline $5 *$ & $100 \times 50 \times 4$ & 100.9 & 49.7 & 3.87 & 4.5 & 100 & 600 & 52.2 & - & - & - \\
\hline 6 & $100 \times 51 \times 1.5$ & 101.5 & 51.6 & 1.53 & 4.5 & 50 & 450 & 9.4 & 1.76 & 0.98 & 2.65 \\
\hline 7 & $100 \times 51 \times 1.5$ & 101.0 & 51.6 & 1.53 & 4.5 & 100 & 600 & 11.6 & 1.64 & 0.94 & 2.57 \\
\hline 8 & $150 \times 64 \times 1.5$ & 150.9 & 64.6 & 1.53 & 4.5 & 50 & 600 & 8.9 & 1.80 & 0.97 & 2.64 \\
\hline 9 & $150 \times 64 \times 1.5$ & 151.1 & 64.6 & 1.53 & 4.0 & 100 & 750 & 10.7 & 1.45 & 0.89 & 2.32 \\
\hline 10 & $200 \times 76 \times 1.5$ & 200.7 & 76.8 & 1.53 & 4.5 & 50 & 750 & 8.4 & 1.81 & 0.95 & 2.60 \\
\hline 11 & $200 \times 76 \times 1.5$ & 201.0 & 76.6 & 1.56 & 4.5 & 100 & 900 & 9.8 & 1.51 & 0.83 & 2.28 \\
\hline 12 & $200 \times 76 \times 2.4$ & 199.8 & 76.2 & 2.44 & 4.5 & 50 & 750 & 21.8 & 1.42 & 1.03 & 2.17 \\
\hline 13 & $200 \times 76 \times 2.4$ & 199.9 & 76.0 & 2.45 & 4.5 & 100 & 900 & 26.8 & 1.33 & 1.00 & 2.27 \\
\hline & & \multicolumn{7}{|c|}{ Mean } \\
\hline
\end{tabular}

Note: * - Test specimen failed due to combined web crippling and bending

$d_{1}$ is calculated using measured depth $(d)$, thickness $\left(t_{w}\right)$ and inside bent radius $\left(r_{i}\right)$

$d_{1}=d-2\left(t_{w}+r_{i}\right)$ 
Table 4. Test specimen details and results for IOF load case

\begin{tabular}{|c|c|c|c|c|c|c|c|c|c|c|c|}
\hline \multirow[t]{2}{*}{ Test } & \multirow{2}{*}{$\begin{array}{l}\text { Unlipped } \\
\text { channel } \\
\text { section }\end{array}$} & \multirow[t]{2}{*}{$\mathrm{d}(\mathrm{mm})$} & \multirow{2}{*}{$\begin{array}{c}\mathrm{b}_{\mathrm{f}} \\
(\mathrm{mm})\end{array}$} & \multirow{2}{*}{$\begin{array}{c}\mathrm{t}_{\mathrm{w}} \\
(\mathrm{mm})\end{array}$} & \multirow{2}{*}{$\begin{array}{c}\mathrm{r}_{\mathrm{i}} \\
(\mathrm{mm})\end{array}$} & \multirow{2}{*}{$\begin{array}{c}\mathrm{lb} \\
(\mathrm{mm})\end{array}$} & \multirow{2}{*}{$\underset{(\mathrm{mm})}{\mathrm{L}}$} & \multirow{2}{*}{$\begin{array}{c}\text { Test } \\
\text { Capacity } \\
(\mathrm{kN})\end{array}$} & \multicolumn{2}{|c|}{$\begin{array}{c}\text { Test/ } \\
\text { AISI S100 }\end{array}$} & \multirow{2}{*}{$\begin{array}{l}\text { Test/ } \\
\text { Euro } \\
\text { code }\end{array}$} \\
\hline & & & & & & & & & (1) & (2) & \\
\hline 14 & $230 \times 75 \times 6$ & 229.8 & 74.4 & 5.90 & 8.0 & 50 & 840 & 144.2 & 0.87 & 0.68 & 0.79 \\
\hline 15 & $230 \times 75 \times 6$ & 230.0 & 74.4 & 5.92 & 8.0 & 100 & 940 & 162.2 & 0.88 & 0.68 & 0.83 \\
\hline 16 & $230 \times 75 \times 6$ & 230.3 & 74.5 & 5.91 & 8.0 & 150 & 1141 & 179.3 & 0.92 & 0.70 & 0.88 \\
\hline 17 & $180 \times 75 \times 5$ & 179.8 & 75.1 & 4.64 & 4.5 & 50 & 689 & 91.5 & 0.84 & 0.67 & 0.79 \\
\hline 18 & $180 \times 75 \times 5$ & 179.8 & 75.0 & 4.61 & 4.5 & 100 & 839 & 105.2 & 0.88 & 0.69 & 0.86 \\
\hline 19 & $180 \times 75 \times 5$ & 179.8 & 75.2 & 4.65 & 4.5 & 150 & 990 & 121.3 & 0.93 & 0.72 & 0.92 \\
\hline 20 & $100 \times 50 \times 4$ & 101.1 & 49.8 & 3.89 & 4.5 & 50 & 450 & 66.0 & 0.86 & 0.68 & 0.80 \\
\hline 21 & $100 \times 50 \times 4$ & 101.1 & 49.8 & 3.84 & 4.0 & 100 & 599 & 78.5 & 0.92 & 0.72 & 0.89 \\
\hline 22 & $100 \times 51 \times 1.5$ & 101.3 & 51.5 & 1.52 & 4.0 & 50 & 450 & 13.0 & 1.16 & 0.77 & 1.00 \\
\hline 23 & $100 \times 51 \times 1.5$ & 100.9 & 51.6 & 1.54 & 4.0 & 100 & 600 & 17.8 & 1.34 & 0.87 & 1.12 \\
\hline 24 & $150 \times 64 \times 1.5$ & 150.9 & 64.5 & 1.54 & 4.5 & 50 & 600 & 13.3 & 1.25 & 0.82 & 1.08 \\
\hline 25 & $150 \times 64 \times 1.5$ & 150.9 & 64.6 & 1.52 & 4.5 & 100 & 750 & 17.5 & 1.48 & 0.93 & 1.21 \\
\hline 26 & $200 \times 76 \times 1.5$ & 200.6 & 76.8 & 1.55 & 4.0 & 50 & 750 & 16.9 & 1.49 & 1.01 & 1.39 \\
\hline 27 & $200 \times 76 \times 1.5$ & 200.9 & 76.6 & 1.56 & 4.5 & 100 & 901 & 18.5 & 1.49 & 0.95 & 1.29 \\
\hline 28 & $200 \times 76 \times 2.4$ & 199.8 & 76.2 & 2.45 & 4.0 & 50 & 750 & 36.4 & 1.16 & 0.86 & 1.13 \\
\hline \multicolumn{9}{|c|}{ Mean } & 1.10 & 0.78 & 1.00 \\
\hline \multicolumn{9}{|c|}{$\mathrm{COV}$} & 0.23 & 0.15 & 0.19 \\
\hline
\end{tabular}

Note: $d_{1}$ is calculated using measured depth $(d)$, thickness $\left(t_{w}\right)$ and inside bent radius $\left(r_{i}\right)$

$$
d_{1}=d-2\left(t_{w}+r_{i}\right)
$$

Table 5. Coefficients currently available and proposed in AISI S100

\begin{tabular}{|c|c|c|c|c|c|c|c|c|}
\hline $\begin{array}{c}\text { Load } \\
\text { case }\end{array}$ & Coefficients & $\mathrm{C}$ & $\mathrm{C}_{\mathrm{r}}$ & $\mathrm{C}_{\mathrm{l}}$ & $\mathrm{C}_{\mathrm{w}}$ & Mean & COV & $\phi_{\mathrm{w}}$ \\
\hline \multirow{3}{*}{ EOF } & AISI S100 (1) & 4.0 & 0.40 & 0.60 & 0.03 & 1.40 & 0.23 & 0.85 \\
\cline { 2 - 9 } & AISI S100 (2) & 4.0 & 0.14 & 0.35 & 0.02 & 0.94 & 0.06 & 0.85 \\
\cline { 2 - 9 } & Proposal & 4.5 & 0.15 & 0.25 & 0.015 & 1.00 & 0.06 & 0.90 \\
\hline \multirow{3}{*}{ IOF } & AISI S100 (1) & 13.0 & 0.32 & 0.10 & 0.01 & 1.10 & 0.23 & 0.85 \\
\cline { 2 - 9 } & AISI S100 (2) & 13.0 & 0.23 & 0.14 & 0.01 & 0.78 & 0.15 & 0.90 \\
\cline { 2 - 9 } & Proposal & 5.1 & 0.10 & 0.30 & 0.001 & 1.00 & 0.07 & 0.90 \\
\hline
\end{tabular}


Table 6. Comparison of test results with proposed design equations for EOF load case

\begin{tabular}{|c|c|c|c|c|c|c|c|c|}
\hline Test & $\begin{array}{l}\text { Unlipped } \\
\text { channel } \\
\text { section }\end{array}$ & $\begin{array}{c}\mathrm{lb}_{\mathrm{b}} \\
(\mathrm{mm})\end{array}$ & $\begin{array}{c}\text { Test } R_{b} \\
(\mathrm{kN})\end{array}$ & $\begin{array}{c}\text { Test/ } \\
\text { AISI S100 } \\
\text { Proposal }\end{array}$ & $\mathrm{k}$ & $\begin{array}{l}\mathrm{R}_{\mathrm{bcr}} \\
(\mathrm{kN})\end{array}$ & $\begin{array}{l}\mathrm{R}_{\mathrm{by}} \\
(\mathrm{kN})\end{array}$ & $\begin{array}{l}\text { Test/ } \\
\text { DSM }\end{array}$ \\
\hline 1 & $230 \times 75 \times 6$ & 100 & 103.9 & 0.91 & 3.19 & 509.4 & 570.7 & 0.95 \\
\hline 2 & $230 \times 75 \times 6$ & 150 & 121.8 & 0.94 & 3.86 & 633.7 & 718.4 & 0.95 \\
\hline 3 & $180 \times 75 \times 5$ & 100 & 72.8 & 0.98 & 3.75 & 381.4 & 384 & 1.01 \\
\hline 4 & $180 \times 75 \times 5$ & 150 & 86.4 & 1.05 & 4.24 & 425.8 & 488.4 & 1.02 \\
\hline 6 & $100 \times 51 \times 1.5$ & 50 & 9.4 & 1.05 & 3.43 & 21.9 & 77.4 & 1.06 \\
\hline 7 & $100 \times 51 \times 1.5$ & 100 & 11.6 & 1.04 & 4.62 & 29.6 & 118.1 & 0.97 \\
\hline 8 & $150 \times 64 \times 1.5$ & 50 & 8.9 & 1.03 & 2.91 & 12.5 & 97.6 & 1.05 \\
\hline 9 & $150 \times 64 \times 1.5$ & 100 & 10.7 & 0.97 & 4.26 & 18.3 & 139 & 1.00 \\
\hline 10 & $200 \times 76 \times 1.5$ & 50 & 8.4 & 0.99 & 2.58 & 8.3 & 118 & 1.00 \\
\hline 11 & $200 \times 76 \times 1.5$ & 100 & 9.8 & 0.90 & 3.62 & 12.4 & 162 & 0.93 \\
\hline 12 & $200 \times 76 \times 2.4$ & 50 & 21.8 & 1.07 & 2.56 & 33.6 & 179.5 & 1.13 \\
\hline 13 & $200 \times 76 \times 2.4$ & 100 & 26.8 & 1.07 & 3.58 & 47.6 & 243.3 & 1.14 \\
\hline \multicolumn{4}{|c|}{ Mean } & 1.00 & & & & 1.02 \\
\hline \multicolumn{4}{|c|}{$\mathrm{COV}$} & 0.06 & & & & 0.06 \\
\hline
\end{tabular}

Table 7. Comparison of test results with proposed design equations for IOF load case

\begin{tabular}{|c|c|c|c|c|c|c|c|c|}
\hline Test & $\begin{array}{l}\text { Unlipped } \\
\text { channel } \\
\text { section }\end{array}$ & $\begin{array}{c}\mathrm{lb}_{\mathrm{b}} \\
(\mathrm{mm})\end{array}$ & $\begin{array}{c}\text { Test } R_{b} \\
(\mathrm{kN})\end{array}$ & $\begin{array}{c}\text { Test/ } \\
\text { AISI S100 } \\
\text { Proposal }\end{array}$ & $\mathrm{k}$ & $\begin{array}{l}\mathrm{R}_{\mathrm{bcr}} \\
(\mathrm{kN})\end{array}$ & $\begin{array}{l}\mathrm{R}_{\text {by }} \\
(\mathrm{kN})\end{array}$ & $\begin{array}{l}\text { Test/ } \\
\text { DSM }\end{array}$ \\
\hline 14 & $230 \times 75 \times 6$ & 50 & 144.2 & 1.02 & 5.71 & 922.1 & 718.1 & 1.02 \\
\hline 15 & $230 \times 75 \times 6$ & 100 & 162.2 & 0.96 & 6.06 & 988.0 & 864.0 & 0.99 \\
\hline 16 & $230 \times 75 \times 6$ & 150 & 179.3 & 0.94 & 6.80 & 1102.0 & 1006.2 & 0.96 \\
\hline 17 & $180 \times 75 \times 5$ & 50 & 91.5 & 1.02 & 6.23 & 625.4 & 448.5 & 1.01 \\
\hline 18 & $180 \times 75 \times 5$ & 100 & 105.2 & 0.99 & 6.85 & 674.9 & 551.1 & 0.99 \\
\hline 19 & $180 \times 75 \times 5$ & 150 & 121.3 & 0.99 & 7.26 & 733.7 & 662.0 & 0.98 \\
\hline 20 & $100 \times 50 \times 4$ & 50 & 25.0 & 1.01 & 6.38 & 671.7 & 239.3 & 1.06 \\
\hline 21 & $100 \times 50 \times 4$ & 100 & 50.0 & 1.01 & 6.61 & 669.1 & 326.0 & 1.03 \\
\hline 22 & $100 \times 51 \times 1.5$ & 50 & 13.0 & 0.91 & 7.12 & 44.6 & 113.9 & 0.89 \\
\hline 23 & $100 \times 51 \times 1.5$ & 100 & 17.8 & 0.97 & 7.39 & 48.3 & 156.2 & 0.97 \\
\hline 24 & $150 \times 64 \times 1.5$ & 50 & 13.3 & 0.93 & 6.17 & 27.0 & 155.4 & 0.89 \\
\hline 25 & $150 \times 64 \times 1.5$ & 100 & 17.5 & 0.98 & 6.07 & 25.5 & 194.0 & 1.04 \\
\hline 26 & $200 \times 76 \times 1.5$ & 50 & 16.9 & 1.15 & 5.73 & 19.2 & 198.3 & 1.10 \\
\hline 27 & $200 \times 76 \times 1.5$ & 100 & 18.5 & 1.00 & 6.67 & 22.8 & 240.7 & 1.00 \\
\hline 28 & $200 \times 76 \times 2.4$ & 50 & 36.4 & 1.13 & 5.72 & 76.1 & 298.6 & 1.11 \\
\hline \multicolumn{4}{|c|}{ Mean } & 1.00 & & & & 1.00 \\
\hline \multicolumn{4}{|c|}{$\mathrm{COV}$} & 0.07 & & & & 0.06 \\
\hline
\end{tabular}

